\title{
POTENCIAL DE BANCARIZAÇÃO DO COOPERATIVISMO DE CRÉDITO NOS MUNICÍPIOS BRASILEIROS DESASSISTIDOS PELO SFN
}

\section{POTENTIAL FOR BANKING CREDIT COOPERATIVISM IN BRAZILIAN MUNICIPALITIES UNATTENDED BY THE SFN}

\author{
Leonardo Custodio Machado ${ }^{1}$ \\ https://orcid.org/0000-0002-4752-0404 \\ Ana Martha Bülow ${ }^{2}$ \\ https://orcid.org/0000-0002-4693-2941
}

Submissão: 30/08/2021 / Aceito: 23/11/2021 / Publicado: 23/11/2021.

\begin{abstract}
Resumo
Este artigo visa quantificar indivíduos e municípios brasileiros sem acesso ao crédito e serviços financeiros através de agência, posto de atendimento ou de atendimento eletrônico, traçar o perfil socioeconômico desta população e avaliar o potencial de bancarização das cooperativas de crédito nesses locais. A democratização do acesso ao crédito e operações bancárias é um desafio no Sistema Financeiro Nacional, principalmente em municípios mais interiorizados, pobres e com menor Índice de Desenvolvimento Humano Municipal (IDHM). Apesar do recente crescimento do Sistema Nacional de Crédito Cooperativo (SNCC), o estudo demonstra que as cooperativas de crédito podem oferecer produtos e serviços financeiros a 392 municípios em 20 estados e 1,64 milhão de pessoas desatendidas. A região Nordeste concentra $66,35 \%$ dos municípios desassistidos e é o mercado financeiro com maior índice de vulnerabilidade social e pobreza, possibilitando ao cooperativismo de crédito atuar como mecanismo de inclusão financeira e desenvolvimento socioeconômico local e regional.
\end{abstract}

Palavras-chave: Cooperativismo de crédito. Desenvolvimento socioeconômico. Potencial de bancarização. Inclusão Financeira.

\begin{abstract}
This article aims to quantify Brazilian individuals and municipalities without access to credit and financial services through a branch, service post or electronic service, to outline the socioeconomic profile of this population and to assess the potential for banking credit unions in these locations. The democratization of access to credit and banking operations is a challenge in the National Financial System, especially in cities which are more inland, poor and with a lower Municipal Human Development Index (IDHM). Despite the recent growth of the National Cooperative Credit System (SNCC), the study

\footnotetext{
${ }^{1}$ Pós-graduado em Marketing Estratégico pela ESPM. Assessor de Comunicação do Sescoop/RS. E-mail: leonardo_cmachado@hotmail.com

${ }^{2}$ Pós-graduada em Marketing Estratégico pela ESPM. Assessora de Comunicação do Sescoop/RS. Email: anamarthabulow@gmail.com
}$$
\text { DOI: https://doi.org/10.46699/rce.v26i42.6644 Edição Vol. 26, Núm. 42, } 2022 .
$$ 
shows credit cooperatives can offer financial products and services to 392 municipalities in 20 states and 1.64 million underserved people. The Northeast region concentrates $66.35 \%$ of underserved municipalities and is the financial market with the highest index of social vulnerability and poverty, enabling credit cooperatives to act as a mechanism for financial inclusion and local and regional socioeconomic development.

Keywords: Credit cooperatives. Socioeconomic development. Banking potential. Financial Inclusion.

\section{INTRODUÇÃO}

A expansão do sistema financeiro e de crédito é fundamental para o desenvolvimento econômico e social dos municípios brasileiros. A democratização do acesso ao crédito e serviços bancários configura um cenário de desafio para o Sistema Financeiro Nacional (SFN), principalmente em municípios mais pobres e isolados, com prevalência de população rural. Nesse sentido, o Sistema Nacional de Crédito Cooperativo (SNCC) se coloca como agente potencial de bancarização e atendimento às necessidades dessas pessoas, na medida em que atua como instrumento de inclusão financeira e social.

Ao mesmo tempo, o Brasil, por suas características geográficas e dimensões territoriais, é um país de muitas oportunidades. Com 5.570 municípios, parece natural que muitas localidades que estão um pouco mais distantes das grandes capitais não tenham à disposição o que outras têm. E é nestes lugares que as cooperativas de crédito encontram um nicho bastante peculiar. Por possuir um foco que visa ao crescimento de seus associados e de suas comunidades, estas cooperativas chegam nestes lugares e impactam na prosperidade e no desenvolvimento local e regional. Conforme Souza (2007), o cooperativismo de crédito pode atuar como instrumento de apoio ao desenvolvimento local tanto na retenção da poupança local, quanto na alocação de recursos a custos relativamente mais baixos em negócios com maior grau de identidade com o município, a região e o Estado-membro.

Segundo o Banco Central do Brasil (2019a), o SNCC apresentou uma curva de crescimento superior ao SFN, atingindo em 2019 a marca de $\mathrm{R} \$ 274$ bilhões em ativos totais, o que representa crescimento 2,7 vezes maior do que o conjunto dos outros segmentos de instituições financeiras. $\mathrm{O}$ incremento na participação de crédito nas operações das cooperativas retrata o aporte cada vez mais forte de recursos nessas operações, cujas captações somaram R $\$ 204$ bilhões ao final de 2019, com destaque para os depósitos a prazo e depósitos à vista, que representam respectivamente $53,7 \%$ e $16,2 \%$ do total de captações.

A quantidade de Postos de Atendimento Cooperativo (PAC) cresceu 12,2\% em 2019, correspondendo a um incremento de 659 unidades. No que concerne à capilaridade do segmento, todas as regiões do país apresentaram crescimento das unidades de atendimento a um número superior de municípios. No comparativo com 2018, a expansão de sedes de cooperativas ou PAC(s) abrangeu 87 novos municípios (BACEN, 2019a).

Conforme o Panorama do Sistema Nacional de Crédito Cooperativo (BACEN, 2019a), em 202 municípios do país a cooperativa de crédito é a única instituição para obtenção de serviços financeiros na própria localidade. Esse número denota o cresci-

DOI: https://doi.org/10.46699/rce.v26i42.6644＜noBreak>Edição Vol. 26, Núm. 42, 2022. 
mento de 8,91\% em relação a 2018, quando existiam 184 municípios nessa mesma circunstância. Em paralelo à expansão dos serviços prestados pelas cooperativas por intermédio dos PAC(s), evidencia-se também o processo de diminuição do número de agências e postos de atendimento bancário (PAB).

Se por um lado, a região Sul concentra ao menos uma sede ou PAC em 93\% dos municípios, o cenário contrasta com a realidade da região Nordeste, onde apenas $11 \%$ dos municípios são atendidos (BACEN, 2019a). Nesse contexto, as cooperativas de crédito apresentam potencial de ampliar a sua área de atuação e estender os serviços financeiros ofertados.

Segundo os Relatórios Estatísticos do Conselho Mundial de Cooperativas de Crédito (WOCCU, 2009; WOCCU, 2019), a taxa de penetração das cooperativas de crédito no Brasil, isto é, o número total de membros de cooperativas de crédito dividido pela população economicamente ativa entre 15 e 64 anos, cresceu 4,41\% entre 2008 e 2018, enquanto que a taxa mundial de penetração registrou expansão de $1,68 \%$ neste mesmo período. Em 2018, a taxa de penetração das cooperativas de crédito no Brasil ficou em 6,91\%, abaixo da média dos países da América Latina (14,57\%). Apesar de aumentar o ritmo de crescimento do SNCC nos últimos anos, o potencial de expansão é notório quando se estabelece uma comparação com a taxa de penetração do cooperativismo de crédito em outros países que se destacam em rankings internacionais, como Estados Unidos (55,17\%), Canadá $(42,60 \%)$ e Coréia do Sul (16,37\%).

Diante do exposto, analisar o potencial de bancarização das cooperativas de crédito em municípios do Brasil que não possuem agência, postos de atendimento ou postos de atendimento eletrônico, bem como o perfil socioeconômico destes municípios, contribui com a literatura ao evidenciar o espaço de crescimento disponível para as cooperativas de crédito e o impacto desta inserção no desenvolvimento econômico sustentável e inclusivo das regiões e do país.

Para identificar o potencial de bancarização, esse estudo considera o perfil socioeconômico dos 202 municípios em que a cooperativa de crédito é a única instituição para obtenção de serviços financeiros na localidade (SANTOS, 2020). A partir da análise envoltória dos dados, foram definidos os limiares de entrada das cooperativas de crédito para novos mercados potenciais. O escopo desse estudo compreende a relação de 30.252 postos de atendimento eletrônico, 20.714 agências e 17.602 postos de atendimento, que representa a amostragem total das entidades supervisionadas pelo Banco Central do Brasil (BACEN, 2020), com data-base em dezembro de 2019. Dada esta contextualização, este trabalho tem como objetivo responder ao seguinte problema de pesquisa:

Qual o potencial de bancarização do cooperativismo de crédito brasileiro nos municípios que não possuem nenhuma agência, posto de atendimento ou posto de atendimento eletrônico, qual a população desassistida nestes locais e qual o perfil socioeconômico desta população?

Essa pesquisa tem como objetivo geral avaliar quantitativamente o potencial de bancarização do SNCC no Brasil e o seu impacto para o desenvolvimento socioeconômico local e regional. Para essa verificação, utilizou-se como base de dados o cenário no mês de dezembro de 2019. 


\section{REVISÃO DE LITERATURA}

\subsection{Natureza das cooperativas de crédito}

Segundo a International Co-operative Alliance - ICA (2019), as cooperativas são entidades centradas nas pessoas, que se unem de forma democrática e igualitária para realizarem as suas aspirações econômicas, sociais e culturais comuns. O modelo de gestão cooperativo compartilha direitos de voto iguais entre os associados, independentemente da sua cota de participação no capital social da cooperativa, tornando o mesmo dono do próprio negócio (ICA, 2018; OCB, 2019). Para Andrezo e Lima (2007), este é o grande diferencial competitivo das cooperativas de crédito em relação aos bancos comerciais.

No que tange aos aspectos regulatórios, o Banco Central do Brasil (BACEN, 2019b) é o órgão regulador que autoriza e supervisiona as cooperativas de crédito no território nacional. De acordo o Bacen (2019b), cooperativa de crédito é uma instituição financeira formada pela associação de pessoas para prestar serviços financeiros exclusivamente aos seus associados, que são ao mesmo tempo donos e usuários da cooperativa, participando de sua gestão e usufruindo de seus produtos e serviços.

Conforme McKillop e Wilson (2010), a natureza do modelo de negócio das cooperativas de crédito permite que a instituição financeira estabeleça um vínculo de envolvimento mais próximo com a comunidade em que está inserida, com capacidade de conhecer mais as necessidades e anseios da população local, possibilitando estratégias de negócios que gerem oportunidades de ganhos tanto para a cooperativa quanto para a comunidade. Segundo McKillop e Wilson (2010, p. 1), "credit unions are selfhelp cooperative financial organizations geared to attaining the economic and social goals of members and wider local communities". Thesing (2018) reforça a ideia e cita o sétimo princípio do cooperativismo, que aponta preocupação das cooperativas com o desenvolvimento sustentável das comunidades, a partir de políticas definidas pelos associados.

Musskopf e Roloff (2002) e Thesing (2018) argumentam que os benefícios das instituições cooperativas às comunidades em que elas atuam vão muito além dos limites de seu quadro social, familiares e colaboradores. "Onde elas atuam a comunidade toda acaba ganhando, até mesmo aquelas pessoas que nunca tomaram conhecimento do cooperativismo" (MUSSKOPF; ROLOFF, 2002, p. 13).

Hanan (2002 apud RAMAMONJIARIVELO; RAUTERKUS, 2010) cita que as cooperativas de crédito representam uma força competitiva e que uma presença consistente dessas instituições financeiras tem um impacto positivo nas taxas de depósitos bancários e de poupança. $\mathrm{O}$ estímulo à concorrência e à expansão do cooperativismo de crédito está presente nas diretrizes da Agenda Estratégica do Banco Central do Brasil Agenda BC\#, especificamente nas dimensões Inclusão e Educação, devido ao potencial de inserção das cooperativas de crédito em locais longínquos do Brasil e a sua capacidade de fomentar o desenvolvimento regional (BACEN, 2019a).

Busanello (2006), Dublin (1969), Menezes (2004) e Pinho (2004) comentam que a cooperativa tem em sua finalidade a prestação de serviços sem intuito lucrativo. Enquanto na empresa capitalista a prestação de serviços é o meio de obter o maior lucro

DOI: https://doi.org/10.46699/rce.v26i42.6644 Edição Vol. 26, Núm. 42, 2022. 
possível, na cooperativa a satisfação das necessidades dos associados é o fim da atividade econômica. O retorno refere-se à distribuição das sobras líquidas resultantes da diferença entre o preço de venda e o preço de compra - distribuição que se efetua pela proporção do rateio das operações que cada associado realiza com a cooperativa (PINHO, 2004).

Segundo Menezes (2004), as cooperativas de crédito não são um negócio financeiro ordinário, que busca enriquecer seus sócios às custas do público em geral. Nem tão pouco se constituem em meras empresas de empréstimos, que visam ao lucro. A cooperativa de crédito é a expressão no campo da economia de um ideal social elevado. Diferente dos bancos comerciais, as cooperativas de crédito reaplicam a poupança dos associados na própria região, contribuindo para estimular seu desenvolvimento e, ao mesmo tempo, corrigir desequilíbrios regionais (PINHO, 2004). Esse modelo estrutural permite às cooperativas de crédito manter a proximidade, a identidade, o relacionamento direto com o associado, compreendendo as suas necessidades, sem perder a capacidade de competir com os bancos comerciais (PAGNUSSATT, 2004).

Na cooperativa, o capital deve ser um fator de produção e não de renda financeira, isto é, o capital em uma cooperativa é um meio e não uma finalidade (FONSECA; VEIGA, 2001). Evidente que o fator econômico é importante e necessário, afinal ninguém se associa a um empreendimento destinado a ter prejuízo. Apesar da sociedade cooperativa não buscar o lucro, ela persegue resultados positivos, como instrumento para viabilizar o negócio de seus associados, dentro da economia de mercado (LEMOS; RICCIARDI, 2000). Entretanto, as cooperativas não se estruturam estrategicamente somente na base de sua acumulação. Dessa forma, a avaliação econômico-financeira de uma cooperativa se baseia na sua capacidade de prestar os serviços necessários e solicitados pelo seu quadro social (FONSECA; VEIGA, 2001).

Crúzio (2005), Fonseca e Veiga (2001) e Schardong (2003) ressaltam que as taxas de juros das cooperativas de crédito são mais baixas do que as praticadas pelos bancos comerciais, além delas realizarem empréstimos aos seus associados sem discriminação e burocracia. Menezes (2004) acrescenta que elas oferecerem juros mais baixos e que os serviços das cooperativas de crédito são mais ágeis e democráticos, sobregulamento que eles próprios, os cooperados, decidirem internamente. Na visão do autor, os bancos comerciais não têm a prática de facilitar negócios para todas as pessoas, sobretudo na concessão de crédito e na abertura de pequenas contas. A cooperativa contrapõe-se a essas amarras, na chamada democratização do serviço bancário.

Na cooperativa de crédito, os depositantes são os associados que têm controle direto sobre o destino dos depósitos. Os sócios das cooperativas de crédito controlam os ganhos das várias operações realizadas com seus depósitos e estes ganhos são depois repartidos entre eles ou reinvestidos, conforme for deliberado na assembleia da cooperativa, inclusive podendo financiar outros empreendimentos cooperativos (FONSECA; VEIGA, 2001).

\subsection{Representatividade do SNCC no Sistema Financeiro Nacional (SFN)}

O cooperativismo de crédito tem registrado crescimento nos últimos anos e cada vez mais aumenta a sua participação na expansão do acesso ao crédito no Brasil, be- 
neficiando especialmente as micro, pequenas e médias empresas, além de pessoas físicas. De acordo com as informações agregadas dos sistemas de Consolidação Contábil das Instituições do Sistema Financeiro Nacional (COSIF apud BACEN, 2019a), o SNCC apresentou, entre 2015 e 2019, expansão de 2,3\% nos ativos totais, $2 \%$ na carteira de crédito e 1,9\% para depósitos. Os ativos totais do SNCC representam 3\% em relação ao SFN, enquanto que a carteira de crédito e os depósitos constituem 4,6\% e 6\%, respectivamente (BACEN, 2019a).

No que se refere ao crescimento da carteira ativa, o saldo das operações de crédito do SNCC superou nos últimos três anos a tendência registrada do SFN (Gráfico 1). Apesar do ciclo de crescimento apresentar sinais de estabilização em 2019, destaca-se o nível de expansão 5 vezes superior ao do SFN, com índice de expansão de $25 \%$ ao ano. Esse resultado se deve à estrutura de composição da carteira de crédito, com predominância das pequenas e médias empresas e de pessoas físicas, sobretudo produtores rurais (BACEN, 2019a).

\section{Gráfico 1 - Crescimento anual da Carteira Ativa}

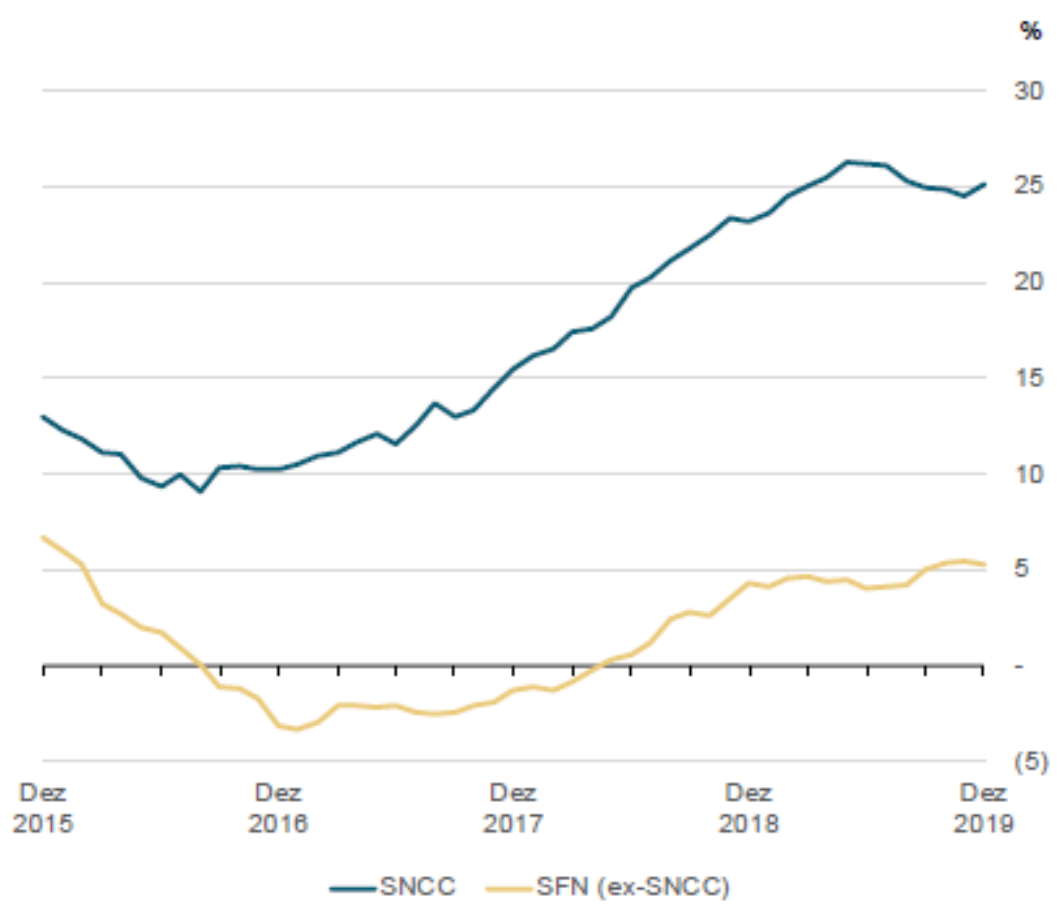

Fonte: BACEN, 2019a, p. 14

A participação das grandes empresas representa apenas $2 \%$ do estoque de crédito do SNCC em dezembro de 2019. Já o crédito rural compreendeu $42 \%$ das operações realizadas com pessoas físicas e apresentou trajetória de expansão de 18\% em 2019 (BACEN, 2019a).

A expansão das operações com recebíveis, capital de giro para pequenas e médias empresas (12,5\% e 25,3\%, respectivamente) e a ampliação de 14,6\% nas operações de crédito rural e $17,3 \%$ em empréstimo pessoal para pessoas físicas impulsionou o 
crescimento de 16,5\% das concessões de crédito em 2019, na comparação com 2018 (BACEN, 2019a).

Tabela 1 - Evolução da Carteira Ativa no SNCC

(continua)

\begin{tabular}{cccccc}
\hline Tipo de cliente/modalidade & Dez 2015 & Dez 2016 & Dez & Dez 2017 & Dez 2019 \\
\hline Pessoa física & 58,3 & 64,4 & 74,0 & 89,6 & 109,7 \\
Consignado & 5,3 & 6,2 & 7,5 & 9,6 & 11,9 \\
Empréstimo pessoal & 12,4 & 13,6 & 15,3 & 18,3 & 22,1 \\
Veículos & 3,6 & 3,1 & 3,1 & 4,1 & 5,3 \\
Habitacional & 0,0 & 0,1 & 0,1 & 0,3 & 0,6 \\
Cartão de crédito & 1,8 & 2,5 & 3,5 & 4,7 & 6,2 \\
Rural & 25,4 & 28,4 & 33,0 & 39,3 & 46,5 \\
Outros créditos & 9,7 & 10,5 & 11,6 & 13,4 & 17,1 \\
\hline Pessoa jurídica & 33,2 & 35,5 & 37,5 & 47,7 & 62,0 \\
Pequenas e médias empresas & 29,3 & 32,1 & 35,1 & 44,8 & 58,6 \\
Capital de giro & 12,5 & 15,6 & 19,1 & 24,5 & 31,5 \\
Investimento & 2,8 & 2,7 & 3,0 & 4,9 & 8,3 \\
Capital de giro rotativo & 3,2 & 3,3 & 3,4 & 3,9 & 4,6
\end{tabular}

Tabela 1 - Evolução da Carteira Ativa no SNCC

(conclusão)

Tipo de cliente/modalidade Dez 2015 Dez 2016 Dez 2017 Dez 2018 Dez 2019

\begin{tabular}{cccccc}
\hline Pessoa jurídica & 33,2 & 35,5 & 37,5 & 47,7 & 62,0 \\
\hline Pequenas e médias empresas & 29,3 & 32,1 & 35,1 & 44,8 & 58,6 \\
\hline Operações com recebíveis & 3,6 & 3,7 & 3,9 & 4,2 & 4,8 \\
Comércio exterior & 0,0 & 0,0 & 0,1 & 0,1 & 0,2 \\
Outros créditos & 3,6 & 3,4 & 3,6 & 4,8 & 6,7 \\
Financ. infraest./Desenv./Projeto & 1,2 & 1,1 & 1,3 & 1,5 & 1,6 \\
Rural e agroindustrial & 2,4 & 2,4 & 0,7 & 0,8 & 0,8 \\
\hline Grandes empresas & 4,0 & 3,4 & 2,4 & 2,9 & 3,4 \\
\hline Total & 91,5 & 99,9 & 111,5 & 137,2 & 171,7 \\
\hline
\end{tabular}

Fonte: SCR apud BACEN, 2019a, p. 14

\subsection{Organização e capilaridade do SNCC}

Segundo o Fundo Garantidor do Cooperativismo de Crédito (FGCOOP), as cooperativas de crédito se organizam em sistemas de primeiro (cooperativas singulares), segundo (centrais) ou terceiro (confederações) grau (nível). As cooperativas singulares ocupam a base, as centrais abrangem a faixa intermediária e as confederações situam-se no topo da estrutura da pirâmide. De acordo com o FGCOOP, 
Cooperativa singular ou de $1^{\circ}$ grau: tem objetivo de prestar serviços diretos ao associado. É constituída por um mínimo de vinte cooperados; Central ou cooperativa de $2^{\circ}$ grau: seu objetivo é organizar, em maior escala, os serviços das filiadas, facilitando a utilização recíproca dos serviços. É constituída por, no mínimo, três cooperativas singulares; Confederação ou cooperativa de $3^{\circ}$ grau: possui personalidade jurídica própria e reúne no mínimo três centrais, com o objetivo de defender seus interesses, promover a padronização, supervisão e integração operacional, financeira, normativa e tecnológica.

O SNCC é formado por quatro sistemas compostos pelos três níveis (Sicoob, Sicredi, Cresol e Unicred) e cinco sistemas compostos de dois níveis (Cecoop, Ailos, Cecrers, CrediSIS e Uniprime). A quantidade de cooperativas singulares passou por um processo de redução de $17,64 \%$ entre 2015 e 2019. No comparativo com 2018, a redução foi de 5,62\%, movimento este conectado principalmente às 45 incorporações registradas nesse período (BACEN, 2019a; FGCOOP).

Em decorrência da mudança de critérios de associação, o número de cooperativas de crédito de livre admissão aumentou para 413, registrando uma expansão de $9,44 \%$ em relação a 2018 e $23 \%$ no comparativo com 2015 , com uma participação de aproximadamente $83 \%$ do ativo total do SNCC. Em contrapartida, as cooperativas de produtor rural e as de crédito mútuo ${ }^{3}$ sofreram um processo de diminuição de $45 \% \mathrm{e}$ $11 \%$, respectivamente (BACEN, 2019a).

Esse crescimento das cooperativas de livre admissão aponta o direcionamento do SNCC na busca da diversificação do perfil dos associados, resultando na otimização de recursos nas estruturas operacionais das instituições e ganho de escala. Conforme a Resolução 4.434, de 5 de agosto de 2015 (BACEN, 2019a, p. 9), as cooperativas são classificadas como

[...] plenas (podem praticar todas as operações), clássicas (não podem ter moeda estrangeira, operar com variação cambial nem com derivativos) ou de capital e empréstimo (não podem captar depósitos, sendo seus recursos oriundos apenas do capital integralizado pelos associados e de empréstimos e repasses).

O cenário em dezembro de 2019 indica a predominância de cooperativas clássicas (656), seguidas das de capital e empréstimo (181) e das plenas (36). Filho (2020, p. 9) destaca que

Nas tratativas entre o Banco Central e o Sistema, foram estabelecidas metas de crescimento, que compõem a Agenda BC\# Cooperativismo - [onde] espera-se que o cooperativismo passe a representar $20 \%$ do crédito no âmbito do Sistema Financeiro Nacional, consideradas as modalidades em que efetivamente atua.

De acordo com a Agenda BC\# (BACEN, 2019a), a estratégia de expansão da rede de atendimento passa pela expectativa de incremento de $35 \%$ no percentual de mu-

\footnotetext{
${ }^{3}$ Segundo Pinheiro (2008, p. 33), o inciso VI da Portaria n ${ }^{\circ} 1.098$ do Ministério da Agricultura estabeleceu que as cooperativas de crédito mútuo são tipos de cooperativas de crédito que congregam como associados somente pessoas que possuem vínculo a uma determinada entidade, corporação ou empresa, com área de ação reduzida, e que realizem operações ativas e passivas apenas com os associados.
}

$$
\text { DOI: https://doi.org/10.46699/rce.v26i42.6644＜noBreak>Edição Vol. 26, Núm. 42, } 2022 .
$$


nicípios atendidos por cooperativas de crédito nas regiões Norte e Nordeste, as quais apresentam os menores percentuais de inserção de cooperativas de crédito singulares em seus municípios, com $26 \%$ e $11 \%$, respectivamente.

\subsection{Evolução de cooperados}

Em dezembro de 2019, o número de cooperados seguiu a trajetória contínua de crescimento registrada desde 2008, atingindo a marca de 10,9 milhões de cooperados, o que representa um crescimento de $159,52 \%$ em relação a 2008 e $10,10 \%$ no comparativo com 2018. A maior alta ocorreu na quantidade de clientes pessoa jurídica (PJ), que cresceu $16,9 \%$, enquanto que o aumento de cooperados pessoas físicas (PF) foi de $8,8 \%$. Dos 10,9 milhões de associados, 9,4 milhões são pessoas físicas e 1,5 milhão são pessoas jurídicas, com as maiores taxas de crescimento no período entre 2018 e 2019 registradas na região Norte, com 21\% em PF e 24,5\% em PJ (BACEN, 2017; BACEN, 2018a; BACEN, 2019a).

Outro fator a se destacar foi o crescimento do percentual da população associada à cooperativa de crédito, que aumentou em todas as regiões do Brasil em 2019, com ênfase às regiões Sul e Centro-Oeste, que apresentaram as maiores variações de incremento de cooperados em relação à população total, no período de 2018 a 2019, com $1,2 \%$ e $0,6 \%$, nessa ordem (BACEN, 2019a).

As regiões Norte e Nordeste são as que apresentam as menores taxas de penetração do segmento, com a maioria dos municípios tendo menos de $1 \%$ da população associada a alguma cooperativa de crédito, realidade que difere bastante da região Sul, onde o cooperativismo de crédito é mais desenvolvido e chega a apresentar índice superior a 25\% de pessoas associadas, em mais de 60\% dos municípios (BACEN, 2019a).

Quanto à faixa etária, a maioria das pessoas físicas que ingressou no segmento cooperativo e se associou à cooperativa de crédito entre dezembro de 2016 e dezembro de 2019 está na faixa entre 20 e 39 anos (53\%), seguido do grupo entre 40 e 59 anos (27\%) e jovens até 20 anos (11\%). Em relação ao gênero, os ingressantes no sistema cooperativo são representados por 55\% masculino e 45\% feminino (BACEN, 2019a).

\subsection{Bancarização}

Segundo a Febraban (2011), o conceito de bancarização está correlacionado ao nível de acesso e ao grau de uso dos serviços financeiros, e não se relaciona com a concepção de ter uma conta corrente em uma instituição financeira. De acordo com a Artemisia (2018), a acepção de bancarização diz respeito somente à questão do acesso aos serviços financeiros, enquanto que a utilização dos mesmos contempla o conceito de inclusão financeira.

Em outras palavras, bancarização é o processo que representa a expansão do número de pessoas que compõem o sistema financeiro, estabelecendo algum tipo de relacionamento junto às instituições financeiras no que concerne aos produtos e serviços

$$
\text { DOI: https://doi.org/10.46699/rce.v26i42.6644 Edição Vol. 26, Núm. 42, } 2022 .
$$


ofertados em alguma localidade. Não obstante os conceitos supracitados, a bancarização desprovida de uma relação de uso qualificada costuma impactar em um público mal servido pelo sistema financeiro, com acesso a produtos e serviços onerosos, de qualidade inferior e juros exorbitantes (ARTEMISIA, 2018).

Além de possuir grande capilaridade no que se refere a pontos de atendimento, o Brasil também é um país que apresenta alto índice de bancarização. No SFN, o processo de bancarização manteve-se estável nos últimos anos. De acordo com o Relatório de Cidadania Financeira (BACEN, 2018b), entre 2015 e 2017, a quantidade de adultos com relacionamento bancário pouco oscilou, sendo que em 2017 mais de 140 milhões $(86,5 \%)$ de pessoas possuíam algum tipo de relacionamento bancário, como contas de depósitos à vista, contas de depósitos de poupança e contas correntes de depósitos de investimento. Os dados analisados incluem todas as contas cadastradas no SFN, contabilizando inclusive as não encerradas, aquelas com saldo muito baixos ou sem registro de operações de saques, depósitos ou transferências por um longo período.

Quanto ao uso de serviços financeiros, outro dado que merece destaque é o da bancarização da sociedade brasileira. Segundo o Relatório de Cidadania Financeira (BACEN, 2018b), 72,3\% dos respondentes da população afirmam que têm ao menos uma conta corrente, conta salário ou conta de poupança. Ao analisar o percentual de bancarização a partir do critério de escolaridade, todavia, percebe-se que somente $51,4 \%$ dos respondentes analfabetos ou com o ensino fundamental incompleto possuem algum tipo de conta. Da mesma maneira, $61,7 \%$ dos respondentes que recebem até dois salários mínimos declaram que têm algum tipo de relacionamento bancário. Esses índices aumentam de acordo com o grau de escolaridade da população, ficando em 59,9\% para nível médio incompleto, $78,2 \%$ para ensino médio completo ou superior incompleto, $93,3 \%$ para superior completo e $100 \%$ para aqueles que declaram ter pós-graduação.

Santos (2013) explica o fenômeno da bancarização a partir de duas dimensões, sob o ponto de vista dos microempreendedores e, por outro lado, a perspectiva quanto à ampliação do acesso a serviços financeiros na população brasileira em geral. Em relação ao primeiro grupo, Santos (2013) afirma que a relação aberta entre as instituições financeiras e os microempreendedores cria oportunidades de negócios que potencializam as chances de sucesso dos empreendimentos através de produtos e serviços bancários. No que tange à sociedade brasileira em geral, o processo de bancarização propicia o surgimento de novos mercados, até então inexistentes, a partir de públicos incipientes ou da consolidação de novos formatos de negócios com públicos já existentes.

A formalidade jurídica da atividade empreendedora coloca o microempreendedor individual em um outro patamar de relacionamento com o mercado, a sociedade e as esferas de poder do Estado. Com isso, a empresa tem a possibilidade de constituir um relacionamento com a instituição financeira em consonância com a sua atividade e potencial de produção. Nesse sentido, a bancarização traz oportunidades de produtos e serviços ofertados pelas instituições financeiras, como empréstimos de capital de giro, financiamentos de aquisições para o negócio, meios de pagamento e recebimento, entre outros recursos disponíveis (SANTOS, 2013).

\section{METODOLOGIA}

DOI: https://doi.org/10.46699/rce.v26i42.6644 Edição Vol. 26, Núm. 42, 2022. 


\subsection{Amostra e coleta de dados}

As informações das agências, postos de atendimento e postos de atendimento eletrônico foram coletadas por meio de arquivos gerados pelo Bacen (2020), disponibilizados no quinto dia útil do mês seguinte à data-base de 31 de dezembro de 2019, período de análise desta pesquisa. O objeto de estudo estabelece correlação com os $202 \mathrm{mu}$ nicípios destacados no Panorama do Sistema Nacional de Crédito Cooperativo (BACEN, 2019a), os quais encontram na cooperativa de crédito a única instituição para obtenção de serviços financeiros na localidade.

A amostra deste estudo é composta por 30.252 postos de atendimento eletrônico, 20.714 agências bancárias e 17.602 postos de atendimento, que incluem os Postos de Atendimento Avançado (PAA), Postos Bancários de Arrecadação e Pagamento (PAP), Postos de Atendimento ao Microcrédito (PAM), Postos de Atendimento Bancário (PAB), Postos de Atendimento Cooperativo (PAC), Postos de Atendimento Transitório (PAT), Postos de Câmbio Permanente (PCP), excetuando-se do escopo de análise os Postos de Compra de Ouro (PCO) por não contemplarem nenhuma instituição financeira do segmento bancário.

Inicialmente, foram avaliados e separados os municípios em que não existem nenhuma agência, posto de atendimento ou posto de atendimento eletrônico, resultando em um grupo de 401 observações. Dentre estes, estabeleceu-se como limiar de entrada para as cooperativas de crédito o município de Engenho Velho (RS), com população de 1.034 habitantes (IBGE, 2010), pelo fato de ser o município com a menor população atendida por uma cooperativa de crédito, no grupo de 202 municípios mencionado anteriormente (SANTOS, 2020). A partir disso, foram excluídos três municípios com população inferior, chegando a uma amostra total de 398 municípios desassistidos.

Além dos dados disponibilizados pelo Bacen (2020), utilizou-se também as estimativas da população residente nos municípios brasileiros com data de referência em $1^{\circ}$ de julho de 2019 (IBGE, 2019a) e indicadores sociais disponibilizados pelo Atlas do Desenvolvimento Humano no Brasil (COSTA; MARQUES; PINTO, 2013), que leva em consideração dados coletados a partir do Censo Demográfico de 2010, Ipea (2010), Programa das Nações Unidas para o Desenvolvimento (PNUD) e Fundação João Pinheiro (FJP). Dentre os indicadores sociais e demográficos analisados constam: área territorial dos municípios, Índice de Desenvolvimento Humano Municipal (IDHM) ${ }^{4}$, faixa do IDHM, renda per capita ${ }^{5}$, PIB per capita ${ }^{6}$, população urbana, população rural,

${ }^{4} \mathrm{O}$ índice de Desenvolvimento Humano Municipal (IDHM) é uma medida composta de indicadores de três dimensões do desenvolvimento humano: longevidade, educação e renda. O índice varia de 0 a 1 , sendo que quanto mais próximo de 1 , maior é o desenvolvimento humano do município (PNUD, 2020).

${ }^{5}$ Conforme Gastaldi (2003, p. 325), “a renda individual ou per capita resulta da divisão da riqueza total e real de um país pelo número de seus habitantes".

${ }^{6}$ O PIB é a soma de todos os bens e serviços finais produzidos por um país, estado ou cidade, geralmente em um ano. O PIB per capita (divisão do PIB pelo número de habitantes) mede quanto do PIB caberia a cada indivíduo de um país se todos recebessem partes iguais (IBGE, 2020).

$$
\text { DOI: https://doi.org/10.46699/rce.v26i42.6644Ｅdição Vol. 26, Núm. 42, } 2022 .
$$


índice de $\mathrm{Gini}^{7}$, percentual de pessoas pobres ${ }^{8}$ e percentual de pessoas extremamente pobres 9 .

A fim de aprimorar a análise e permitir uma caracterização melhor dos municípios brasileiros atendidos por algum Posto de Atendimento Cooperativo, utilizou-se o indicador social de PIB per capita. Diante das informações disponibilizadas, foi possível obter dados do PIB até 2017 (IBGE, 2017). Foram excluídos das observações quatro municípios que registram PIB per capita inferior ao PIB per capita de Cedro do Abaeté (MG), município que apresenta o menor PIB per capita dentre todos aqueles que são atendidos por alguma cooperativa de crédito no Brasil. Dessa forma, a amostra final ficou composta por 392 municípios, distribuídos conforme a Tabela 2. A pesquisa também analisou informações geográficas coletadas a partir do IpeaData (1998), com a finalidade de mensurar a interiorização dos municípios em cada região brasileira (Tabela 3). A base de dados utilizada é mais atual, vigente em 2000, e compreende a distância destes municípios às suas respectivas capitais estaduais.

Tabela 2 - Distribuição dos municípios sem agência, posto de atendimento ou posto de atendimento eletrônico

\begin{tabular}{c|c|c|c|c}
\hline Norte & Nordeste & Centro-Oeste & Sudeste & Sul \\
\hline 43 & 238 & 23 & 75 & 13 \\
\hline
\end{tabular}

Fonte: Resultado da pesquisa, elaboração própria.

Tabela 3 - Média das distâncias dos municípios desassistidos à capital estadual por região $(\mathrm{em} \mathrm{km})$

\begin{tabular}{c|c|c|c|c}
\hline Norte & Nordeste & Centro-Oeste & Sudeste & Sul \\
\hline 313,5 & 191,38 & 277,5 & 259,33 & 261,7 \\
\hline \multicolumn{5}{c}{ Fonte: Resultado da pesquisa, elaboração própria. }
\end{tabular}

A Tabela 4 exprime a descrição das variáveis utilizada no escopo de análise.

Tabela 4 - Descrição das variáveis utilizadas

\begin{tabular}{cccccc}
\hline Região & Norte & Nordeste & Centro-Oeste & Sudeste & Sul \\
\hline População & 180.541 & 1.085 .557 & 64.634 & 272.618 & 32.785
\end{tabular}

7 "Constitui uma das medidas usuais para medir o grau de concentração de renda de uma certa localidade, região ou sociedade” (PINHO; VASCONCELLOS, 2003, p. 407).

${ }^{8}$ Proporção dos indivíduos com renda domiciliar per capita igual ou inferior a R\$ 140,00 men-sais, em reais de agosto de 2010. Refere-se a indivíduos que vivem em domicílios particulares permanentes (COSTA; MARQUES; PINTO, 2013).

${ }^{9}$ Proporção de indivíduos com renda domiciliar per capita igual ou inferior a $\mathrm{R} \$ 70,00$ mensais, em reais de agosto de 2010. Refere-se a indivíduos que vivem em domicílios particulares permanentes (COSTA; MARQUES; PINTO, 2013).

$$
\text { DOI: https://doi.org/10.46699/rce.v26i42.6644 Edição Vol. 26, Núm. 42, } 2022 .
$$




\begin{tabular}{cccccc} 
Área $\left(\mathrm{km}^{2}\right)$ & $70.435,81$ & $116.778,48$ & $15.713,99$ & $21.892,18$ & $4.180,84$ \\
IDHM & 0,62 & 0,572 & 0,687 & 0,656 & 0,689 \\
Renda Per Capita (R\$) & 317,43 & 237,74 & 506,78 & 413,77 & 521,3 \\
PIB Per Capita (R\$) & $57.395,53$ & $44.608,27$ & $54.157,41$ & $61.556,42$ & $72.601,76$ \\
População Urbana (\%) & 61,94 & 46,33 & 65,11 & 57,87 & 56,10 \\
População Rural (\%) & 38,06 & 53,67 & 34,89 & 42,13 & 43,90 \\
Extremamente pobres (\%) & 19,36 & 26,16 & 4,56 & 8,47 & 4,13 \\
Pobres (\%) & 35,73 & 44,64 & 13,08 & 20,98 & 10,42 \\
Índice de Gini & 0,54 & 0,51 & 0,46 & 0,45 & 0,44 \\
\hline
\end{tabular}

Fonte: Resultado da pesquisa, elaboração própria.

\section{2 Índice de Gini}

Pinho e Vasconcellos (2003) explicam que o índice de Gini ou coeficiente de Gini é obtido com base na curva de Lorenz. Ela nos indica o quanto uma proporção acumulada de renda, representada no eixo vertical, pode variar conforme a proporção acumulada da população, representada no eixo horizontal. O índice de Gini aponta variação de zero a 1, sendo que zero representa a situação de total igualdade, ou seja, todos possuem a mesma renda, e o valor 1 significa completa desigualdade de renda, isto é, se uma só pessoa detém toda a renda do lugar. 


\section{Gráfico 1 - Representação da Curva de Lorenz}

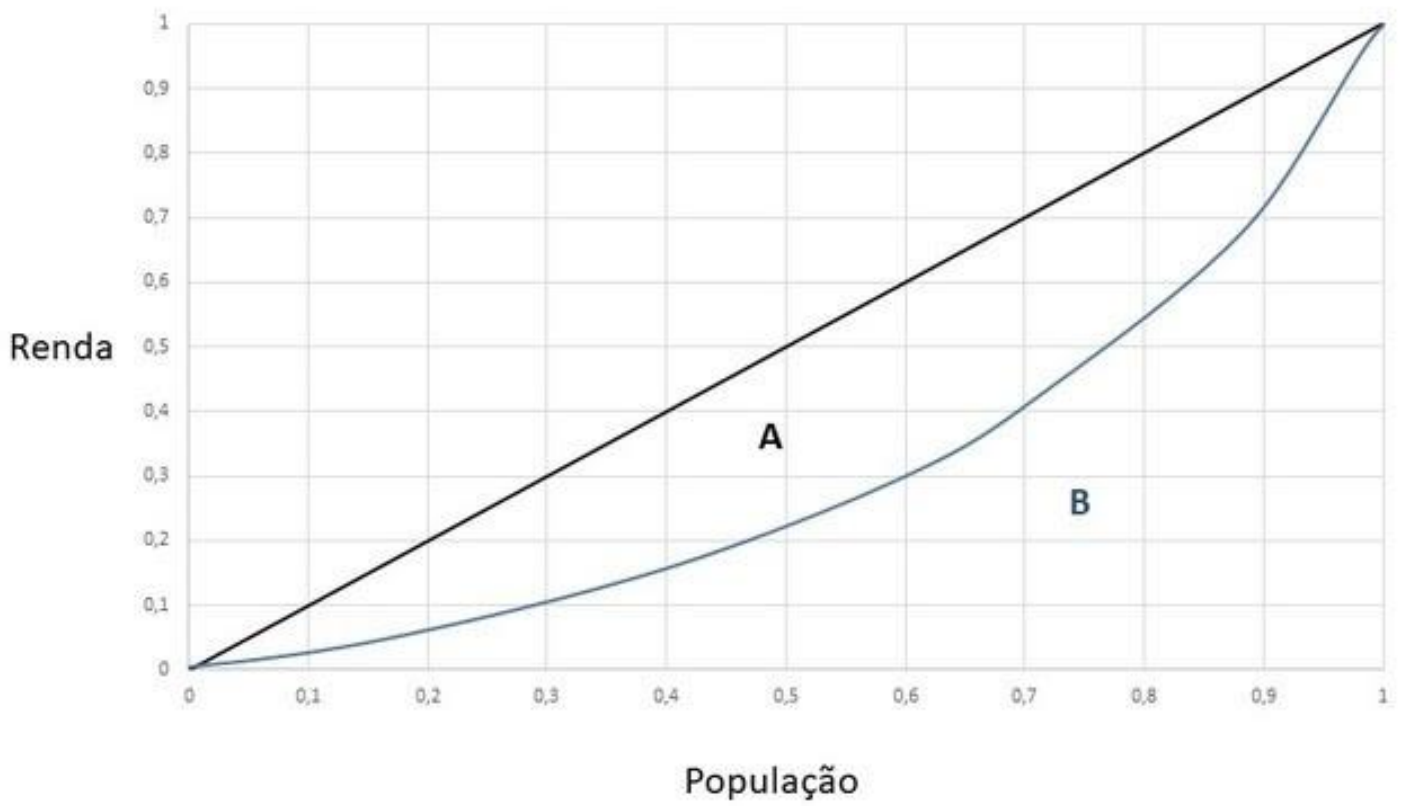

Fonte: Dicionário Financeiro, 2017

Conforme o Gráfico 1, a curva toma como base a distribuição totalmente igualitária de renda, através da representação da linha de cor preta, enquanto a curva de Lorenz de cor azul, representa a desigualdade da renda. Ao analisar a curva de Lorenz, o índice de Gini determina a diferença entre a área da mais perfeita distribuição de renda e aquela que de fato acontece, representado pela fórmula:

$\mathrm{G}=\mathrm{A} /(\mathrm{A}+\mathrm{B})$

$A$ - área de desigualdade observada

$(\mathrm{A}+\mathrm{B})$ - área triangular de total igualdade de renda.

Quanto maior a área observada em A, maior o índice de Gini e maior a desigualdade. A fórmula (DICIONÁRIO FINANCEIRO, 2017) para calcular o coeficiente de Gini utiliza um somatório de toda a área abaixo da curva, subtraído de 1 , sendo a seguinte:

$$
\begin{aligned}
& \mathrm{G}=1-\sum_{i=1}^{k=n-1}\left(\mathrm{P}_{\mathrm{k}+1}-\mathrm{P}_{\mathrm{k}}\right)\left(\mathrm{R}_{\mathrm{k}+1}+\mathrm{R}_{\mathrm{k}}\right) \\
& \mathrm{G} \text { - coeficiente de Gini } \\
& \mathrm{P} \text { - proporção acumulada da "população" } \\
& \mathrm{R} \text { - proporção acumulada de "renda" }
\end{aligned}
$$

Ao calcularmos todo o somatório em uma região de distribuição perfeita, o resultado apresentado será 1, e seu coeficiente de Gini igual a zero, representando total igualdade de renda. A variável do índice de Gini soma-se à renda per capita, percentual de pobres e percentual de extremamente pobres, permitindo traçar o perfil socioeconô-

$$
\text { DOI: https://doi.org/10.46699/rce.v26i42.6644Edição Vol. 26, Núm. 42, } 2022 .
$$


mico do mercado potencial de bancarização para as cooperativas de crédito (DICIONÁRIO FINANCEIRO, 2017).

\subsection{Método estatístico}

A escolha pelo método estatístico está diretamente relacionada a obter, de análises de conjuntos de informações complexos, representações simples e constatar se essas verificações simplificadas possuem relações entre si. Dessa forma, o método estatístico possibilita a redução de fenômenos sociológicos e econômicos a termos quantitativos e a manipulação estatística, que permite justamente comprovar as relações que os fenômenos apresentam entre si, obtendo a partir dessa análise generalizações sobre sua natureza, ocorrência ou significado (LAKATOS; MARCONI, 2009).

A estatística é mais do que apenas uma descrição racional, ela representa um método de experimentação e prova, já que se constitui em um método de análise (LAKATOS; MARCONI, 2009). Segundo Freitas e Prodanov (2009), o método estatístico tem como base a aplicação da teoria estatística da probabilidade e constitui relevante auxílio para a investigação de fenômenos das ciências sociais, sendo bastante aceito por pesquisadores com preocupações de ordem quantitativa. Nesse sentido, o método reforça e comprova conclusões obtidas.

\section{RESULTADOS E DISCUSSÕES}

O primeiro desafio foi quantificar e traçar o perfil socioeconômico dos municípios brasileiros que não possuem agência bancária, posto de atendimento ou posto de atendimento eletrônico, com a finalidade de avaliar o potencial impacto de bancarização das cooperativas de crédito nesses municípios. A partir dessa análise, aplicaram-se como limiares de entrada para as cooperativas de crédito o número de habitantes mínimo (1.034) e PIB per capita igual ou superior a $\mathrm{R} \$ 17.486,00$ (menor PIB per capita registrado em município com PAC). 
Gráfico 2 - Composição da população

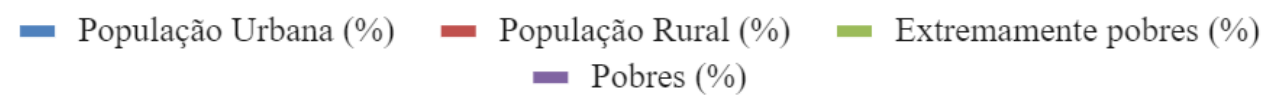

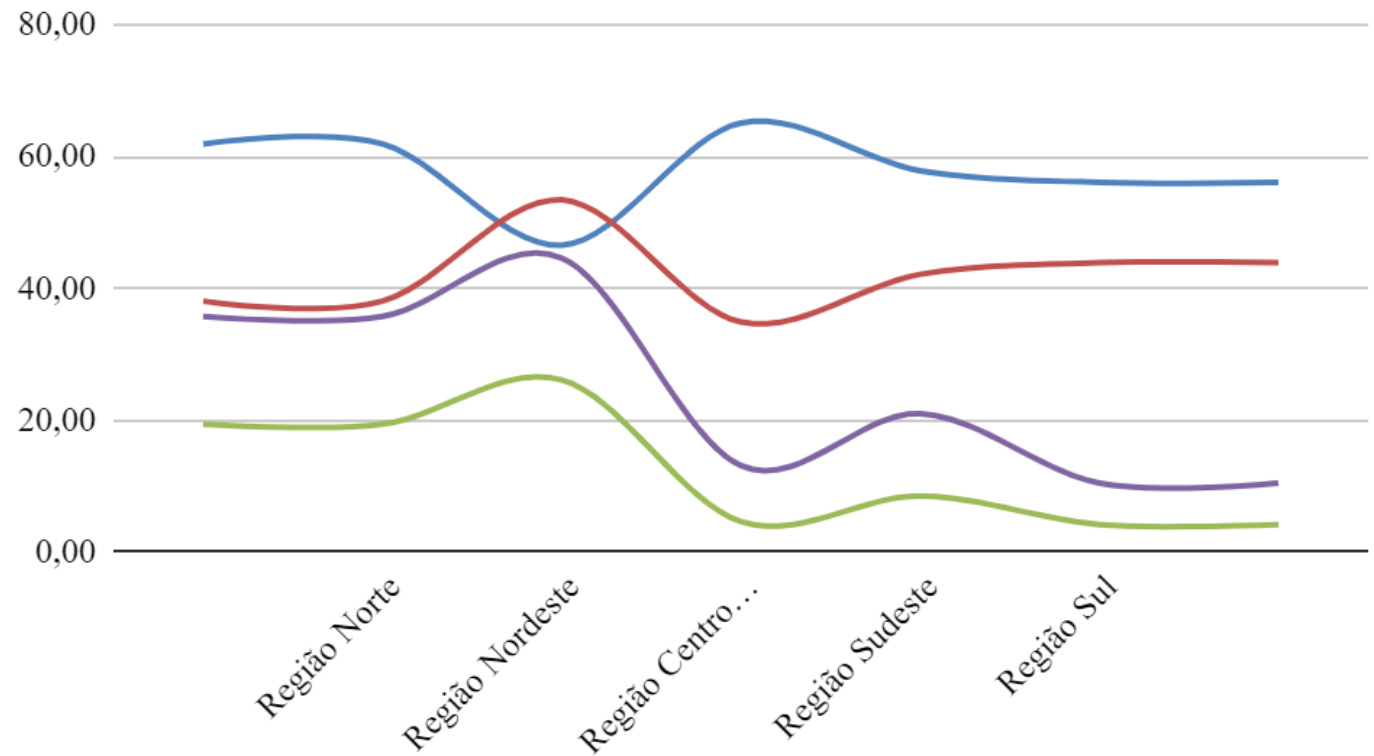

Fonte: Resultado da pesquisa, elaboração própria.

Com base na apuração dos indicadores socioeconômicos e demográficos apresentados, percebe-se que o perfil desse mercado potencial é predominantemente urbano (Gráfico 2), com uma média nacional de população urbana de 57,1\%. A região Nordeste concentra $66,35 \%$ da população sem acesso a serviços financeiros na própria localidade e representa a única onde existe uma população rural superior à urbana. Os estados do Piauí (94 municípios), Paraíba (64 municípios) e Rio Grande do Norte (49 municípios) representam cerca de $87 \%$ dos municípios sem serviços financeiros na região Nordeste e $52,81 \%$ da amostra total.

No que concerne à avaliação da distância dos municípios sem acesso a serviços financeiros às suas respectivas capitais estaduais (Tabela 3), evidencia-se que este público reside em áreas mais isoladas, com uma média de distância equivalente a 261 quilômetros $(\mathrm{km})$. A região Norte apresenta a maior média, com $313,5 \mathrm{~km}$, enquanto a menor média é da região Nordeste, com 191,38 km. Dentre os municípios analisados na amostra, $10(2,54 \%)$ situam-se a menos de $50 \mathrm{~km}$ da capital estadual, 61 (18\%) entre 50 e $100 \mathrm{~km}, 94(23,86 \%)$ entre 100 e $200 \mathrm{~km}$ e $229(58,12 \%)$ acima de $200 \mathrm{~km}$ da capital de seu respectivo estado.

Nos exercícios de simulação, quando consideramos as variáveis macroeconômicas como métricas para potencial de mercado (Tabela 4), a região Nordeste apresenta a situação de maior vulnerabilidade social e desigualdade na distribuição de renda, tanto para IDHM, renda per capita, PIB per capita, população pobre e extremamente pobre, e índice de Gini. 
As cooperativas de crédito têm o potencial de estender a cobertura de produtos e serviços financeiros a 1.636.135 pessoas presentes em 392 municípios desatendidos no Brasil, o que representa mais de $7 \%$ de todos municípios do território nacional, com abrangência em 20 unidades da federação das cinco regiões do país.

Quanto ao Índice de Desenvolvimento Humano, que mede as dimensões longevidade, educação e renda, o mercado potencial de bancarização apresenta perfil homogêneo em todos os 20 estados da amostra, com a média de IDHM dos municípios analisados de um mesmo estado inferior à média da respectiva unidade da federação. Os locais que deflagram a discrepância mais acentuada no comparativo do IDHM são Acre $(25,64 \%)$, Amapá $(18,64 \%)$, Pernambuco $(18,42 \%)$ e Bahia $(17,27 \%)$.

\section{Gráfico 3 - Análise comparativa de IDHM e Índice de Gini}

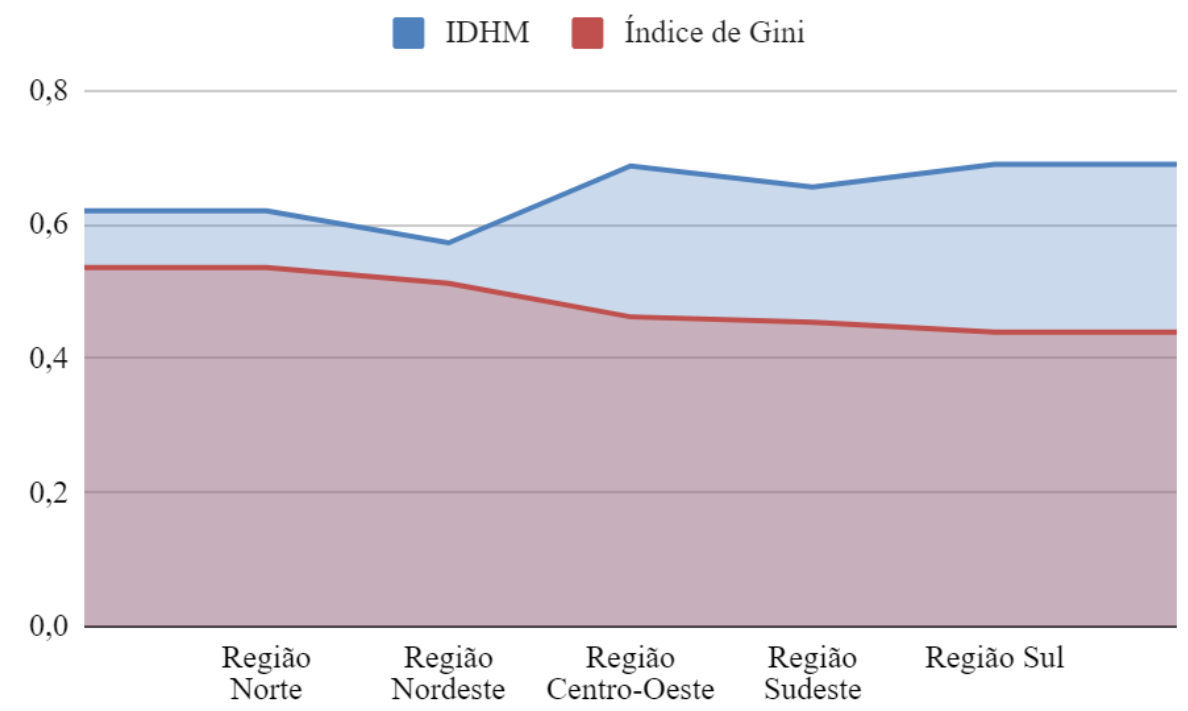

Fonte: Resultado da pesquisa, elaboração própria.

Nota-se que as regiões Norte e Nordeste apresentam os maiores valores médios dos índices de Gini (0,54 e 0,51, respectivamente), o que explicita uma maior desigualdade de renda, enquanto a região Sul possui o valor médio que mais se aproxima de zero na amostra $(0,44)$, demonstrando menor desigualdade.

$\mathrm{Na}$ análise do IDHM, percebe-se uma repetição das regiões. Temos a região Nordeste com o valor médio mais baixo $(0,572)$, seguida da região Norte, com o valor médio no índice igual a 0,620 . Em contraste, novamente a região Sul apresenta o valor mais alto, igual a 0,689. As regiões Nordeste e Norte apresentam os menores valores de desenvolvimento humano, e a região Sul apresenta o maior valor no território nacional. 


\section{CONSIDERAÇÕES FINAIS}

O objetivo deste estudo foi avaliar o potencial de bancarização do cooperativismo de crédito brasileiro nos municípios que não possuem nenhuma agência, posto de atendimento ou posto de atendimento eletrônico, bem como mensurar a população desassistida nestes locais e o perfil socioeconômico desta população. Devido às características e especificidades do modelo de negócio, as cooperativas de crédito têm um papel relevante na democratização do acesso ao crédito e serviços financeiros, constituindo-se em um potencial agente na educação e inclusão financeira de seus associados, especialmente em municípios mais isolados, pobres e com menor índice de desenvolvimento humano.

Por sua ampla capilaridade no território nacional, as cooperativas de crédito impactam o desenvolvimento socioeconômico local e regional de milhares de brasileiros. Essa premissa encontra sustentação no modelo associativo de negócio, que não visa lucro e distribui entre os associados as sobras resultantes de suas atividades, o que permite às cooperativas ofertarem seus produtos e serviços financeiros com taxas mais acessíveis, beneficiando os associados e a comunidade como um todo.

Os resultados obtidos através da análise do mercado potencial demonstram que o cooperativismo de crédito brasileiro tem grande capacidade de crescimento e ampliação do alcance de seus produtos e serviços financeiros, podendo beneficiar mais de 1,64 milhão de indivíduos e 392 municípios atualmente sem agência, posto de atendimento ou posto de atendimento eletrônico, sobretudo na região Nordeste, que concentra $66,35 \%$ da população desbancarizada.

Tendo em vista os aspectos observados, sugere-se como continuidade de pesquisa a aplicação deste estudo para projeções de cenários em anos subsequentes, a fim de acompanhar o processo de bancarização de cooperativas de crédito em municípios brasileiros desassistidos e o impacto dessa expansão no desenvolvimento socioeconômico local e regional.

\section{REFERÊNCIAS}

ANDREZO, Andrea F.; LIMA, Iran Siqueira. Mercado financeiro: aspectos conceituais e históricos. 3. ed. São Paulo: Atlas, 2007.

ARTEMISIA. Tese de impacto social em serviços financeiros: oportunidades para negócios. São Paulo, 2018. Disponível em: https://artemisia.org.br/servicosfinanceiros/. Acesso em: 04 ago. 2020.

BACEN - BANCO CENTRAL DO BRASIL. Panorama do sistema nacional de crédito cooperativo: data-base dezembro/2017. Brasília, 2017, 23 p. Disponível em: https://www.bcb.gov.br/pre/microFinancas/coopcar/pdf/panorama_de_cooperativas 201 7.pdf. Acesso em: 25 jul. 2020.

BACEN - BANCO CENTRAL DO BRASIL. Panorama do sistema nacional de crédito cooperativo: data-base dezembro/2018. Brasília, 2018a, 23 p. Disponível em:

$$
\text { DOI: https://doi.org/10.46699/rce.v26i42.6644Edição Vol. 26, Núm. 42, } 2022 .
$$


https://www.bcb.gov.br/content/estabilidadefinanceira/coopcredpanorama/9 panorama sncc_2018.pdf. Acesso em: 25 jul. 2020.

BACEN - BANCO CENTRAL DO BRASIL. Relatório de cidadania financeira 2018. Brasília, 2018b, 146 p. Disponível em: https://www.bcb.gov.br/Nor/relcidfin/docs/Relatorio_Cidadania_Financeira.pdf. Acesso em: 20 jul. 2020.

BACEN - BANCO CENTRAL DO BRASIL. Panorama do sistema nacional de crédito cooperativo: data-base dezembro/2019. Brasília, 2019a, 28 p. Disponível em: https://www.bcb.gov.br/content/estabilidadefinanceira/coopcredpanorama/panorama_co operativas_sncc_2019.pdf. Acesso em: 25 jul. 2020.

BACEN - BANCO CENTRAL DO BRASIL. O que é cooperativa de crédito?. 2019b. Disponível em:

https://www.bcb.gov.br/acessoinformacao/legado?url=https:\%2F\%2Fwww.bcb.gov.br \%2Fpre\%2Fcomposicao\%2Fcoopcred.asp. Acesso em: 28 jul. 2020.

BACEN - BANCO CENTRAL DO BRASIL. Relação de Agências, Postos e Filiais de Administradoras de Consórcio (transferência de arquivos). Brasília, 2020. Disponível em: https://www.bcb.gov.br/fis/info/agencias.asp?frame=1. Acesso em: 21 jun. 2020.

BUSANELLO, Raquel Bohnen. Processo de mudança em uma organização cooperativa: o caso do Sistema de Crédito Cooperativo SICREDI. Dissertação de Mestrado. Pontifícia Universidade Católica do Rio Grande do Sul, Porto Alegre, 2006. 104 p.

COSTA, Marco Aurélio; MARQUES, Maria Luiza de Aguiar; PINTO, Daniela Gomes (coord.). Atlas do Desenvolvimento Humano nos Municípios. 2013. Disponível em: http://www.atlasbrasil.org.br/2013/pt/perfil/. Acesso em: 8 jun. 2020.

CRÚZIO, Helnon de Oliveira. Como organizar e administrar uma cooperativa. 4. ed. Rio de Janeiro: FGV, 2005. 156 p

DICIONÁRIO FINANCEIRO. Índice de Gini: o que é e como é calculado? Gini do Brasil e do mundo. 2017. Disponível em: https://www.dicionariofinanceiro.com/indicede-gini/. Acesso em: 5 jul. 2020.

DUBLIN, Jack. Uniones de credito: teoria y practica. Cidade do México, México: Editorial Roble, 1969.

FEBRABAN - FEDERAÇÃO BRASILEIRA DE BANCOS. Bancarização e inclusão financeira no Brasil. São Paulo, jul. 2011. Disponível em: https://www.febraban.org.br/7Rof7SWg6qmyvwJcFwF7I0aSDf9jyV/sitefebraban/BAN

$$
\text { DOI: https://doi.org/10.46699/rce.v26i42.6644 Edição Vol. 26, Núm. 42, } 2022 .
$$


CARIZACAO\%20-

\%20III\%20Congresso $\% 20$ Latino $\% 20$ Americano $\% 20 \mathrm{de} \% 20$ bancarizacao $\% 20 \mathrm{e} \% 20 \mathrm{Mic}$ rofinancas \%20-\%20FELABAN\%20-\%20JUNHO\%202011\%20-\%20FINAL.pdf. Acesso em: 04 ago. 2020.

FGCOOP - FUNDO GARANTIDOR DO COOPERATIVISMO DE CRÉDITO.

SNCC: uma visão sobre a organização das cooperativas. Brasília. Disponível em: https://www.fgcoop.coop.br/sncc. Acesso em: 22 jul. 2020.

FILHO, Harold Paquete Espínola. Crescimento e inclusão financeira. Rio Grande Cooperativo, Porto Alegre, ano 6, n. 18, p. 6-9, 2020. Disponível em:

http://www.sescooprs.coop.br/app/uploads/2020/05/rio-grande-cooperativo-semestre-1ed-18-1.pdf. Acesso em: 6 ago. 2020.

FONSECA, Isaque; VEIGA, Sandra Mayrink. Cooperativismo: uma revolução pacífica em ação. Rio de Janeiro: DP\&A: Fase, 2001. 112 p.

FREITAS, Ernani Cesar de; PRODANOV, Cleber Cristiano. Metodologia do trabalho científico: métodos e técnicas da pesquisa e do trabalho acadêmico. Novo Hamburgo, RS: Feevale, 2009. 288 p.

GASTALDI, J. Petrelli. Elementos de economia política. 18. ed. São Paulo: Saraiva, 2003.

IBGE. Engenho Velho. Rio de Janeiro, 2010. Disponível em:

https://www.ibge.gov.br/cidades-e-estados/rs/engenho-velho.html. Acesso em: 23 jun. 2020.

IBGE. Produto interno bruto dos municípios. Rio de Janeiro, 2017. Disponível em: https://sidra.ibge.gov.br/tabela/5938. Acesso em: 23 jun. 2020.

IBGE. Estimativas da população residente no Brasil e unidades da federação com data de referência em $\mathbf{1}^{\mathbf{0}}$ de julho de 2019. Rio de Janeiro, 2019a. Disponível em: ftp://ftp.ibge.gov.br/Estimativas_de_Populacao/Estimativas_2019/estimativa_dou_2019 .xls. Acesso em: 21 jun. 2020.

IBGE. Produto Interno Bruto - PIB: o que é o PIB. Rio de Janeiro, 2019b. Disponível em: https://www.ibge.gov.br/explica/pib.php. Acesso em: 23 jun. 2020.

ICA - INTERNATIONAL CO-OPERATIVE ALLIANCE. What is a cooperative?. 2018. Disponível em: https://www.ica.coop/en/cooperatives/what-is-a-cooperative. Acesso em: 5 jul. 2020.

IPEA - Instituto de Pesquisa Econômica Aplicada. Distância à capital estadual para os municípios da divisão político administrativa vigente em 2000. Brasília, 1998. Disponível em: https://www.ipea.gov.br/ipeageo/bases.html. Acesso em: 07 ago. 2020. 
IPEA - Instituto de Pesquisa Econômica Aplicada. Brasil: índice de desenvolvimento humano - IDH - em 2010. Brasília, 2010. Disponível em:

https://www.ipea.gov.br/ipeageo/bases.html. Acesso em: 06 ago. 2020.

LAKATOS, Eva Maria; MARCONI, Marina de Andrade. Fundamentos de metodologia científica. 6. Ed. São Paulo: Atlas, 2009. 315 p.

LEMOS, Roberto Jenkins de; RICCIARDI, Luiz. Cooperativista, a empresa do século XXI: como os países em desenvolvimento podem chegar a desenvolvidos. São Paulo: LTr, 2000. 183 p.

MCKILLOP, Donal G. WILSON, John O.S. Credit unions: a theoretical and empirical overview. 2010. School of Management at The Queen's University of Belfast, Belfast, 2010. 78 p. Disponível em: http://dx.doi.org/10.2139/ssrn.1702782. Acesso em: 12 ago. 2020.

MENEZES, Antônio. Cooperativa de crédito: o que é e quais seus benefícios. Brasília: Stilo, 2004.

MUSSKOPF, Helio Lailheno; ROLOFF, Fritz. Cooperativismo: um rumo e um ideal. Porto Alegre: Imprensa Livre, 2002.

OCB - ORGANIZAÇÃO DAS COOPERATIVAS BRASILEIRAS. O que é cooperativismo. 2019. Disponível em: https://somoscooperativismo.coop.br/o-que-ecooperativismo. Acesso em: 5 jul. 2020.

PAGNUSSATT, Alcenor. Guia do cooperativismo de crédito: organização, governança e políticas corporativas. Porto Alegre: Sagra Luzzatto, 2004. 194 p.

PINHEIRO, Marcos Antonio Henriques. Cooperativas de crédito: história da evolução normativa no Brasil. 6. ed. Brasília: BCB, 2008, 92 p. ISBN 85-99863-03-7

PINHO, Diva Benevides; VASCONCELLOS, Marco Antonio Sandoval de (Org.). Manual de economia. 4. ed. São Paulo: Saraiva, 2003.

PINHO, Diva Benevides. O cooperativismo no Brasil: da vertente pioneira à vertente solidária. São Paulo: Saraiva, 2004. 357 p.

PNUD - PROGRAMA DAS NAÇÕES UNIDAS PARA O DESENVOLVIMENTO. O que é o IDHM. 2020. Disponível em:

https://www.br.undp.org/content/brazil/pt/home/idh0/conceitos/o-que-e-o-idhm.html. Acesso em: 14 jul. 2020. 
RAMAMONJIARIVELO, Zo; RAUTERKUS, Andreas. Why choose a credit union? Determinants of credit union deposits. 2010. University of Alabama at Birmingham and Governors State University, Birmingham, 2010. 13 p. Disponível em: http://dx.doi.org/10.2139/ssrn.1571335. Acesso em: 12 ago. 2020.

SANTOS, Carlos Alberto dos (Coord.). Pequenos negócios: desafios e perspectivas serviços financeiros. v. 5. Brasília: SEBRAE, 2013, 392 p. ISBN 978-85-7333-583-5. Disponível em: http://www.caixa.gov.br/Downloads/educacao-financeira/educacaoempreendedora.pdf. Acesso em: 22 jul. 2020.

SANTOS, Gustavo Martins dos. Solicitação de informações: estudo sobre inclusão financeira nas cooperativas de crédito [mensagem pessoal]. Mensagem recebida por <leonardo-machado@sescooprs.coop.br> em 15 jun. 2020.

SCHARDONG, Ademar. Cooperativa de crédito: instrumento de organização econômica da sociedade. 2. Ed. Porto Alegre: Riegel, 2003. 128 p.

SOUZA, Edson Galdino Vilela de. Panorama atual do cooperativismo de crédito no Brasil: globalização, estado e cidadania. 2007. Dissertação (Mestrado em Direito Cooperativo e Cidadania) - Universidade Federal do Paraná, Curitiba, 2007. 226 p.

THESING, Nelson José. Por um mundo melhor: cooperação e desenvolvimento. Porto Alegre: Sescoop/RS, 2018.

WOCCU - WORLD COUNCIL OF CREDIT UNIONS. Statistical Report 2008. Madison, WI; Washington, DC, USA, 2009. Disponível em:

https://www.woccu.org/documents/2008_Statistical_Report. Acesso em: 20 jul. 2020.

WOCCU - WORLD COUNCIL OF CREDIT UNIONS. Statistical Report 2018. Madison, WI; Washington, DC, USA, 2019. Disponível em:

https://www.woccu.org/documents/2018_Statistical_Report. Acesso em: 20 jul. 2020. 